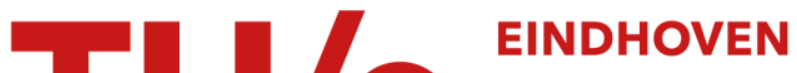 \\ UNIVERSITY OF \\ TECHNOLOGY
}

\section{Fano coupling in perturbed solid acid hydroxyls}

Citation for published version (APA):

Santen, van, R. A. (1994). Fano coupling in perturbed solid acid hydroxyls. Recueil des Travaux Chimiques des Pays-Bas, 113(10), 423-425. https://doi.org/10.1002/recl.19941131003

DOI:

10.1002/recl. 19941131003

Document status and date:

Published: 01/01/1994

\section{Document Version:}

Publisher's PDF, also known as Version of Record (includes final page, issue and volume numbers)

\section{Please check the document version of this publication:}

- A submitted manuscript is the version of the article upon submission and before peer-review. There can be important differences between the submitted version and the official published version of record. People interested in the research are advised to contact the author for the final version of the publication, or visit the $\mathrm{DOI}$ to the publisher's website.

- The final author version and the galley proof are versions of the publication after peer review.

- The final published version features the final layout of the paper including the volume, issue and page numbers.

Link to publication

\section{General rights}

Copyright and moral rights for the publications made accessible in the public portal are retained by the authors and/or other copyright owners and it is a condition of accessing publications that users recognise and abide by the legal requirements associated with these rights.

- Users may download and print one copy of any publication from the public portal for the purpose of private study or research.

- You may not further distribute the material or use it for any profit-making activity or commercial gain

- You may freely distribute the URL identifying the publication in the public portal.

If the publication is distributed under the terms of Article 25fa of the Dutch Copyright Act, indicated by the "Taverne" license above, please follow below link for the End User Agreement:

www.tue.nl/taverne

Take down policy

If you believe that this document breaches copyright please contact us at:

openaccess@tue.nl

providing details and we will investigate your claim. 


\title{
Fano coupling in perturbed solid acid hydroxyls ${ }^{\text {a }}$
}

\author{
R.A. van Santen \\ Schuit Institute of Catalysis, Laboratory of Inorganic Chemistry and Catalysis, Eindhoven University \\ of Technology, P.O. Box 513, 5600 MB Eindhoven, The Netherlands \\ (Received December 8, 1993)
}

\begin{abstract}
A simple analytical expression for the Evans window in the infrared absorption spectrum of hydrogen-bonded basic molecules in protonic zeolites is presented. The expression shows that the essential parameters are the position of the shifted "uncoupled" $\mathrm{OH}$ stretching frequency, its width, the position of the in-plane bending overtone and the coupling of this mode with the $\mathrm{OH}$ stretching mode. Analysis of the Fermi resonances in the $\mathrm{OH}$ stretching band profile provides a method to determine whether adsorbed molecules are hydrogen bonded or protonated.
\end{abstract}

\section{Introduction}

The chemical bond of strongly acidic protons attached to oxygen atoms in the micropores of zeolitic materials is a prototype of non-classical covalent bonding in a solid. In the zeolitic Brønsted acidic site the classically divalent oxygen connects a four-valent $(\mathrm{Si})$ and three-valent (e.g., Al) lattice atom and has also a strong covalent bond with the acidic hydrogen atom. As a consequence the hydrogen-oxygen bond is weakened compared to the bond strength of a free silanol group. This is the basis of the Brønsted acidic nature of protonic zeolites. The nonclassical bonding geometry of the bridging hydroxyls in the alumino-silicate $Y$ has recently been analyzed in detail by solid-state NMR spectroscopy ${ }^{1}$. Acid zeolites are extensively used as solid acidic catalysts.

The dependence of the proton-oxygen bond strength on structure (nearly 90 different topologies exist ${ }^{2}$ ) as well as lattice composition is not well understood, notwithstanding extensive theoretical ${ }^{3}$ as well as experimental investigations ${ }^{4}$.

An attractive approach to the characterization of the nature of the $\mathrm{OH}$ bond is to study its response to weakly interacting basic molecules ${ }^{5}$. The response of the $\mathrm{OH}$ bond can be followed by measuring the changes in frequency and intensity of the infrared (IR) absorption of the $\mathrm{OH}$ absorption band. Using IR spectroscopy this response has not only been measured for the $\mathrm{OH}$ stretching frequencies, but recently also for the in-plane bending modes of deuterated hydroxyl bonds. The deuterated hydroxyl in-plane bending modes ${ }^{6}$ shift to $\sim 880 \mathrm{~cm}^{-1}$. Its location in the infrared transparent lattice vibrational window, makes it directly observable by IR transmission spectroscopy.

Interaction of a basic molecule with the zeolitic $\mathrm{OH}$ bond weakens this bond. This results in a downward shift of the

a Dedicated to Prof. Dr. W.M.H. Sachtler on the occasion of his 70th birthday.
OH stretching frequency. Because the motion of the inplane and out-plane $\mathrm{OH}$ bending modes becomes more restricted, these mode frequencies shift upwards ${ }^{7}$.

The acidic $\mathrm{OH}$ bond is highly polarizable. Upon interaction of the basic molecule, a considerable dipole develops resulting in a significant increase of the intensity of $a b-$ sorption of the $\mathrm{OH}$ stretching mode. Proton-NMR data confirm the increase in positive charge on the proton due to its interaction with the basic molecule ${ }^{8}$. Apart from the downwards shift in IR frequency and increased absorption intensity, there is also a broadening of the shifted $\mathrm{OH}$ stretching frequency. This broadening is a characteristic of hydrogen bonding ${ }^{9}$. It results from the coupling of the downwards shifted $\mathrm{OH}$ stretching frequency with the low-frequency motion of the adsorbate against the zeolitic proton. Due to the high density of these modes, the IR absorption broadens. Its width is proportional to the shift of the $\mathrm{OH}$ stretching frequency.

Interestingly, whereas one expects the appearance of one new band corresponding to the shifted $\mathrm{OH}$ frequency, in some cases the shifted stretching frequency appears to give rise to two new peaks. This phenomenon is the subject of the present article. It has been observed for the interaction of the hydroxyl with acetone ${ }^{10}$, methanol ${ }^{11}$, and water ${ }^{12}$, as well as acetonitrile ${ }^{13}$. Earlier we suggested an explanation based on Fermi resonance ${ }^{13}$, later supported by extensive experimental evidence ${ }^{7}$. The bands were assigned to be the A,B bands of a strongly perturbed hydrogen bonded system. Here we will provide a short theoretical analysis of the phenomenon and show that this type of Fermi resonance is related to the Fano type of resonance ${ }^{14}$, characteristic of the coupling of a discrete level with another broad continuous band system. The splitting of the shifted and broadened $\mathrm{OH}$ stretching bond frequencies into two sub-bands occurs when the interaction with the absorbing base is so strong that the shifted band system overlaps with overtones of the $\mathrm{OH}$ bending modes. The fundamental $\mathrm{OH}$ in-plane bending mode ${ }^{15}$ is approximately $1100 \mathrm{~cm}^{-1}$. This mode is estimated to shift to $1350 \mathrm{~cm}^{-1}$ upon interaction with a strong base ${ }^{7}$. The first overtone of the shifted in-plane $\mathrm{OH}$ bond is located at $2700 \mathrm{~cm}^{-1}$. The absorption inten- 


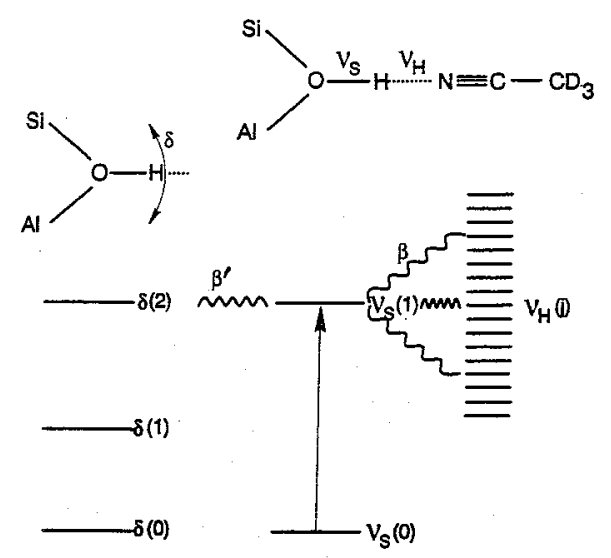

Figure 1. Mode-coupling scheme for interaction of $\mathrm{CD}_{3} \mathrm{CN}$ with zeolite proton. $\delta$ is the in-plane bending mode. $\nu_{s}$ is the stretching mode. Only $\nu_{s}$ can be excited from the ground state.

sity for overtone excitation is very low. Anharmonic coupling of this sharp mode with the broadened downward shift $\mathrm{OH}$ stretching bond leads to intensity stealing. This result in a dip in the broad stretching frequency band system at $\sim 2700 \mathrm{~cm}^{-1}$. Peaks in the absorption spectrum appear around $2500 \mathrm{~cm}^{-1}$ and $2800 \mathrm{~cm}^{-1}$ due to the absorbing probability left in the origin band system.

Because of the strong lattice absorption of zeolites around $1300 \mathrm{~cm}^{-1}$, the upwards shifted $\mathrm{OH}$ in-plane bending modes are not directly observable by IR transmission spectroscopy. However, they are observable for deuterated hydroxyls. Table I provides a comparison of the measured shifted in-plane (OD) modes, interacting with $\mathrm{CD}_{3} \mathrm{CN}$ and $\mathrm{CCl}_{3} \mathrm{CN}$ and the observed Fermi resonance window positions that appear as a dip in the disturbed stretching frequency band system ${ }^{7}$. Similar Fermi window resonances have been observed in the hydrogen bond spectra by Evans ${ }^{16}$ in liquids. Ratajzak et al. ${ }^{17}$ have proposed such an Evans window for perturbed hydroxyl groups in $\mathrm{CsSeO}_{4}$. Here we will present a derivation of an analytical expression for Fano coupling of a single nonoptically excitable state (the $2 \delta$ overtone), with the optically excitable quasi-continuum provided for by the shifted $\mathrm{OH}$ stretching bond.

\section{Resonance theory of the Evans transmission window}

The $(A, B)$ IR bond system corresponds to the mode coupling scheme depicted in Figure $1 . \beta^{\prime}$ and $\beta$ are the coupling parameters of the in-plane bending overtone frequency $2 \delta$ to the $\mathrm{OH}$ stretching frequency $\nu_{\mathrm{s}}$ and the low frequency modes $\nu_{\mathrm{H}, \mathrm{j}}$, corresponding to the vibrations of the hydrogen-bonded adsorbate molecule, respectively. $\beta$ is a measure of the bandwidth of shifted OH stretching frequency. The transition probability follows from the Golden-rule expression

$W \approx \sum_{i}\left\{\left|\left\langle\phi_{0}|\vec{p}| \psi_{\mathrm{i}}\right\rangle\right|^{2} \cdot \delta\left(h \cdot \nu-E_{i}+E_{0}\right)\right\}$

(Eqn. 1):

$\psi_{\mathrm{i}}$ is the vibrational eigenfunction of the coupled system and $\phi_{0}$, the vibrational eigenfunction corresponding to the ground state. $\vec{p}$ is the vibrational dipole-moment operator. $\nu$ is the frequency of electromagnetic radiation. Eqn. 1 can be rewritten in terms of the uncoupled modes $\phi_{\mathrm{i}}$ to give Eqn. 2.

$$
W \approx-\frac{1}{\pi} \cdot \operatorname{Im} \cdot \sum_{\alpha, \beta}\left\{\left\langle\phi_{0}|\vec{p}| \phi_{\alpha}\right\rangle \cdot G_{\alpha \beta} \cdot\left\langle\phi_{\beta}|\vec{p}| \phi_{0}\right\rangle\right\}
$$

The Green function matrix element $G_{\alpha \beta}$ is defined as in Eqn. 3,

$$
G_{\alpha \beta}=\lim _{\epsilon \rightarrow 0}\left\langle\phi_{\alpha}\left|\frac{1}{(E+i \cdot \epsilon) \hat{I}-\hat{H}}\right| \phi_{\beta}\right\rangle ; E=h \cdot \nu+E_{0}
$$

where $\hat{I}$ is the unit operator and $\hat{H}$ the Hamiltonian of the coupled system.We will solve Eqn. 2 assuming that interaction with IR radiation only excites the uncoupled $\nu_{\mathrm{s}}$ modes. This implies Eqn. 4.

$$
\left\langle\phi_{0}|\vec{p}| 2 \cdot \delta\right\rangle=\left\langle\phi_{0}|\vec{p}| \nu_{H, i}\right\rangle=0
$$

Using resolvent theory ${ }^{1,2}$, one deduces the Eqn. 5 for $G_{\nu_{\mathrm{s}}, \nu_{\mathrm{s}}}$ :

$$
G_{\nu_{s}, \nu_{\mathrm{s}}}=\frac{1}{E+i \cdot \epsilon-\epsilon_{\nu_{\mathrm{s}}}-\beta^{\prime 2} \cdot \frac{1}{E-\epsilon_{2 \delta}}-\beta^{2} \cdot g_{\nu_{\mathrm{s}}, \nu_{\mathrm{s}}}}
$$

the Green function of the shifted stretching frequency $\nu_{\mathrm{s}}$; $\epsilon_{\nu_{s}}$ corresponds to the $0 \rightarrow 1$ stretching vibration excitation energy and $\epsilon_{2 \delta}$ to the excitation energy of overtone bending mode.

In order to evaluate Eqn. 5 one has to know $g_{v_{s},}$. For convenience, we will assume it to be the elliptic function that is the solution of the Cayley tree problem ${ }^{18}$

$\lim _{\epsilon \rightarrow 0} g_{\nu_{\mathrm{s}}, \nu_{\mathrm{s}}}=\frac{E-\epsilon_{\nu_{\mathrm{s}}}}{2 \cdot \beta^{2}}-\frac{1}{2 \cdot \beta^{2}} \cdot \sqrt{-4 \cdot \beta^{2}+\left(E-\epsilon_{\nu_{\mathrm{s}}}\right)^{2}}$

(Eqn. 6). The use of this approximation provides an analytical expression for Eqn. 2.

The density of states of the excited $\nu_{\mathrm{s}}$ model, uncoupled from $2 \delta$ but coupled to $\nu_{\mathbf{H}_{\mathbf{j}} \mathbf{j}}$ then becomes as in Eqn. 7.

$$
\begin{aligned}
\rho_{\nu_{\mathrm{s}}}^{0} & =-\frac{1}{\pi} \cdot I m \cdot g_{\nu_{\mathrm{s}}, \nu_{\mathrm{s}}} \\
& =\frac{1}{2 \pi \cdot \beta^{2}} \cdot \sqrt{4 \cdot \beta^{2}-\left(E-\epsilon_{\nu_{\mathrm{s}}}\right)^{2}} ;\left(\left|E-\epsilon_{\nu_{\mathrm{s}}}\right|^{2}<4 \cdot \beta^{2}\right)
\end{aligned}
$$

Using Eqn. 6, an explicit expression for $W$ can be found, that is valid as long as $\left|\beta^{\prime}\right| \ll|\beta|$. This is the so-called weak coupling limit. A general solution to Eqn. 5 can also be found, as discussed extensively elsewhere ${ }^{18}$. In the weak-coupling limit, use Eqn. 6 leads to Eqn. 8 .

$$
\begin{aligned}
W(E) \approx & \left.\left\langle\phi_{0}|\vec{p}| \nu_{\mathrm{s}}\right\rangle\right|^{2} \\
& \left\{\frac{1}{2} \cdot \sqrt[2]{4 \cdot \beta^{2}-\left(E-\epsilon_{\nu_{\mathrm{s}}}\right)^{2}}\right\} \\
& \times\left\{\left(\frac{1}{2} \cdot E-\frac{1}{2} \cdot \epsilon_{\nu_{\mathrm{s}}}-\beta^{\prime 2} \cdot \frac{1}{E-\epsilon_{2 \delta}}\right)^{2}\right. \\
+ & \left.\frac{1}{4} \cdot\left[4 \cdot \beta^{2}-\left(E-\epsilon_{\nu_{\mathrm{s}}}\right)^{2}\right]\right\}^{-1}
\end{aligned}
$$

Table I $\delta(O D)$ band and transmission window minimum ${ }^{a}$.

\begin{tabular}{|c|c|c|c|c|c|c|}
\hline \multicolumn{2}{|c|}{ Brønsted } & \multicolumn{3}{|c|}{$\mathrm{CD}_{3} \mathrm{CN}$ adsorption } & \multicolumn{2}{c|}{$\mathrm{CCl}_{3} \mathrm{CN}$ adsorption } \\
\hline site & $\delta(\mathrm{OD})$ & $\delta(\mathrm{OD})$ & shift & window & $\delta(\mathrm{OD})$ & shift \\
\hline SiODAL & 894 & 988 & 94 & 1977 & 970 & 76 \\
SiODFe & 865 & 950 & 85 & 1902 & 930 & 65 \\
\hline
\end{tabular}




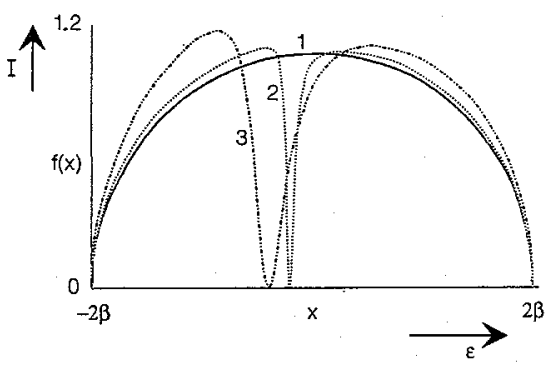

Figure 2. Evans window for a few different values of $\beta^{\prime}$ and $\epsilon_{\nu_{s}}-\epsilon_{2 \delta}$ according to Eqn. $8,4 \beta$ is the phonon frequency bandwidth, $\beta^{\prime}$ the coupling parameter of the in-plane and stretching vibrational modes. 1: $\beta^{\prime}=0$, the Fermi resonance

2: $\beta^{\prime}=0.2 \beta ; \epsilon_{2 \delta}=\epsilon_{y_{s}}-0.1 \beta$

3: $\beta^{\prime}=0.4 \beta ; \epsilon_{2 \delta}=\epsilon_{\nu_{s}}-0.2 \beta$

Eqn. 8 can be considered a generalization of the Fano expression ${ }^{14}$ for auto-ionization, with strong excitation of the continuum wavefunction.

The major extension of the Fano result is that now the energy dependence of the density of states of the quasicontinuum is explicitly accounted for. Eqn. 8 is plotted in Figure 2 as a function of $\beta^{\prime}$ for a few values of $\epsilon_{\nu_{s}}-\epsilon_{2 \delta}$.

\section{Discussion and conclusion}

The theoretical results illustrate that the two maxima (A,B features) in the experimental hydrogen-bonding spectra are a signature of a disturbed hydrogen stretching bond in resonance with a non-optically active mode. The A,B double peaks belong to the shifted $\mathrm{OH}$ stretching mode. The average position of the disturbed $\mathrm{OH}$ stretching frequency bond system is related to the weighted average of the frequencies in the A,B region. Disappearance of the two-peak spectrum for strongly interacting bases may indicate formation of protonated ionic intermediates. An example is provided by the spectra of adsorbed $\mathrm{NH}_{3}{ }^{19}$. Now strong adsorptions are found in the region between $2000-3000 \mathrm{~cm}^{-1}$. There is no indication for a Fermi resonance. The spectrum is to be described as that of disturbed $\mathrm{NH}_{4}^{+}$. In the case of methanol weak $A, B$ bands are observed and an increase of intensities at lower frequencies ${ }^{11}$. This indicates a highly disturbed lowfrequency hydrogen bond that is close to the protonated intermediate, but still has to be described as hydrogenbonded methanol 20 .

Sachtler et al. ${ }^{20}$ have studied the interaction of metal atoms and clusters with zeolitic $\mathrm{OH}$ stretching modes. The interaction with zeolitic protons prevents metal particle agglomerization. The IR spectra indicate a decrease in intensity of the shifted IR OH stretching frequencies. Analysis of spectral features in the A,B spectral region would confirm the proposal that the $\mathrm{OH}$ bonds are highly disturbed and that the metal atoms can be considered to be in a state that is close to that of the protonated state, but with a strong lattice-hydrogen bond.

\section{References}

1 D. Freude, J. Klinowsky and H. Hamdan, Chem. Phys. Lett. 149, 355 (1988); D. Fenzke, M. Hunger and H. Pfeifer, J. Magn. Res. 95, 477 (1991).

2 W.M. Meier and D.H. Olson, Atlas of Zeolite Structure types, Butterworths 1987.

3 J. Sauer, Chem. Rev. 89, 199 (1989); G.J. Kramer and R.A. van Santen, J. Am. Chem. Soc. 115, 2887 (1993); G.J. Kramer, A. de Man and R.A. van Santen, J. Am. Chem. Soc. 113, 6435 (1991); K.P. Schroder, J. Sauer, M. Leslie, C.R.A. Catlow, J. Thomas, Chem. Phys. Lett. 188, 320 (1992); E.G. Derouane and J.G. Fripiat, J. Phys. Chem. 91, 145 (1987); P.J. O'Malley and J. Dwyer, Chem. Phys. Lett. 143, 97 (1988); J.B. Nicholas, R.E. Winaus, R.J. Harrison, L.E. Iton, L.A. Curtiss and A.J. Hopfinger, J. Chem. Phys. 96, 10247 (1992); H.V. Brand, L.A. Curtiss and L.E. Iton, J. Phys. Chem. 96, 7725 (1992); A.G. Pelmenchikov, V.I. Pavlov, G.M. Zhidomirov and S. Baran, J. Phys. Chem. 91, 3325 (1987); W.J. Mortier and P. Geerlings, J. Phys. Chem. 84, 1982 (1980).

4. J.A. Rabo and G.J. Gajda, Catal. Rev. Sci. Techn. 31, 385 (19891990); V.B. Kazansky, Acc. Chem. Res. 24, 379 (1991); R. Beaumont and D. Barthomeuf, J. Catal. 26, 218 (1972); D. Barhtomeuf and R. Beaumont, J. Catal. 30, 45 (1973); B. Beagley, J. Dweyer, F.R. Fitch, R. Mann and J. Wolters, J. Phys. Chem. 88, 1744 (1984).

5 J. Datka, M. Boczar and P. Rymarowicz, J. Catal. 144, 368 (1988); S.G. Hedge, P. Ratnasaing, L.M. Kustov and V.B. Kazansky, Zeolites 8, 137 (1988); L. Kubelkova, S. Beron and J. Lercher, Zeolites 9, 539 (1989).

6 W.P.J.H. Jacobs, J.H.M.C. van Wolput and R.A. van Santen, Chem. Phys. Lett. 210, 32 (1993).

7 W.P.J.H. Jacobs, J.H.M.C. van Wolput, R.A. van Santen and H. Jobic, Zeolites in press; A.G. Pelmenchikov, J.H.M.C. van Wolput, $J$. Jänchen and R.A. van Santen in preparation.

8 J.W. de Haan and L.J.M. v.d. Ven, unpublished.

9 G.C. Pimentel and A.L. McClellan, The hydrogenbond, Reinhold Publ. Co., New York 1960.

${ }^{10} L$. Kubelkova, J. Novakova and $K$. Nedomova, J. Catal. 124, 441 (1990); L. Kubelkova, J. Cejka and J. Novakova, Zeolites 11, 48 (1991).

11 G. Mirth, J.A. Lercher, M.W. Anderson and J. Klinowsky, J. Chem. Soc. Far. Trans. 86, 3039 (1990).

12 L.M. Parker, D.M. Bibby and G.R. Burns, Zeolites 13, 107 (1993); A. Jentys, G. Warecka, M. Derewenski and J.A. Lercher, J. Phys. Chem. 93, 4837 (1989); A. Jentys, G. Waredin and J. Lercher, J. Mol. Catal. 57, 309 (1989); A.G. Pelmenchikov and R.A. van Santen, J. Phys. Chem. 97, 10678 (1993).

13 A.G. Pelmenchikov, R.A. van Santen, J. Jänchen and E. Meyer, J. Phys. Chem. 97, 11071 (1993).

14 U. Fano, Phys. Rev. 124, 1866 (1961); R.A. van Santen, Physica 62, 51 (1972).

15 W.P.J.H. Jacobs, H. Jobic, J.H.M.C. van Wolput and R.A. van Santen, Zeolites 12, 315 (1992); L.M. Kustov, V.R. Borovkov and V.B. Kazansky, J. Catal. 72, 149 (1981); J. Sauer, J. Mol. Catal. 54, 312 (1989); H. Jobic, J. Catal. 131, 289 (1991).

16 J.C. Evans, Spectrochim. Acta 16,994 (1960); M.F. Clydon and N. Sheppard, Chem. Comm. 1969, 1431.

17 H. Ratajak, H.M. Yaremko and J. Baran, J. Mol. Struct. 275, 235 (1975).

${ }^{18}$ R.A. van Santen, Theoretical Heterogeneous Catalysis, World Scientific 1991, p. 76-101; R.A. van Santen and L. Vogel, A.W. Solid State Chem. 1, 151 (1989).

19 E.H. Teunissen, W.P.J.M. Jacobs, A.P.J. Jansen and R.A. van Santen, in "Proc. 9th Int. Zeolite Conference", R. Ballmooss ed., Montreal 1992, Butterworth 1993 I, p. 529.

20 W.M.H. Sachtler, Acc. Chem. Res. 26, 383 (1993); L.L. Steu, H. Knözinger and W.M.H. Sachtler, J. Am. Chem. Soc. 111, 8125 (1989). 